\title{
PEMANFAATAN LAHAN BEKAS TEMPAT PEMBUANGAN AKHIR DENGAN STABILISASI TANAH SECARA KIMIAWI
}

\author{
Satya Bodhinanda ${ }^{1}$ dan Aniek Prihatiningsih ${ }^{2}$ \\ ${ }^{1}$ Program Studi Sarjana Teknik Sipil, Universitas Tarumanagara, Jl. Letjen S. Parman No.1 Jakarta \\ satya.325170035@stu.untar.ac.id \\ ${ }^{2}$ Program Studi Sarjana Teknik Sipil, Universitas Tarumanagara, Jl. Letjen S. Parman No.1 Jakarta \\ aniekp@ft.untar.ac.id
}

Masuk: 11-02-2021, revisi: 05-02-2021, diterima untuk diterbitkan: 17-02-2021

\begin{abstract}
Landfill soil (TPA) has great potential of utilization in construction purpose. Landfill soil has similar characteristic with clay soil that has high water content also contain organic and inorganic material caused by garbage heap. One of the problems in utilizing landfill soil was the low quality of the soil that cause big settlement for the structure. Settlement was an important aspect in performing a construction. Soil stabilization for the landfill soil needed to decrease amount of settlement. Structure model using one, two, three, four floor of load and calculate the settlement occur on the heaviest load location of the foundation. Foundation base was circle and using shallow foundation reconsidering shallow foundation effective for four floor loads. Chemical stabilization using 2 methods: Sodium Hydroxide 6\% and Limestone 3-4,5\%. Based on the calculation, found that Sodium Hydroxide is more effective in decreasing settlement occurred and able to decrease the settlement until 32,42\% for the floor load. However, those methods can't fulfil the $15 \mathrm{~cm}$ settlement limit.
\end{abstract}

Keywords: landfill soil, shallow foundation, chemical stabilization, settlement

\begin{abstract}
ABSTRAK
Tanah bekas tempat pembuangan akhir (TPA) memiliki potensi besar untuk dimanfaatkan dalam bidang konstruksi. Tanah bekas TPA umumnya memiliki karakteristik serupa dengan tanah lempung berkadar air serta memiliki material organik dan anorganik dari timbunan sampah. Salah satu masalah dalam memanfaatkan tanah bekas TPA adalah rendahnya kualitas tanah yang mengakibatkan penurunan besar pada struktur. Perbaikan pada tanah bekas TPA diperlukan untuk mengurangi besarnya penurunan yang terjadi. Penurunan merupakan aspek penting dalam suatu perancangan konstruksi, maka dari itu batasan pada penurunan ditetapkan untuk menghindari penurunan yang berlebihan yang dapat merusak struktur. Permodelan menggunakan beban struktur 1,2,3, dan 4 lantai dan dihitung penurunan yang terjadi pada fondasi dengan beban struktur terbesar. Penampang fondasi berbentuk lingkaran mempertimbangkan beban percobaan hingga 4 lantai cocok untuk fondasi dangkal. Stabilisasi tanah secara kimiawi menggunakan 2 metode yaitu Sodium Hidroksida 6\% dan batu kapur 3-4,5\%. Berdasarkan hasil perhitungan, didapati stabilisasi menggunakan Sodium Hidroksida lebih efektif dalam mengurangi penurunan tanah yang terjadi dan mampu mengurangi besarnya penurunan hingga 32,42\% pada beban struktur 4 lantai. Namun, stabilisasi tanah menggunakan kedua metode belum dapat mencapai batas aman penurunan sebesar $15 \mathrm{~cm}$.
\end{abstract}

Kata kunci: tanah bekas tempat pembuangan akhir, fondasi dangkal, stabilisasi kimiawi, penurunan

\section{PENDAHULUAN}

Tanah tempat pembuangan akhir (TPA) sering dianggap sebagai tanah berkualitas rendah dikarenakan kontaminasi air lindi akibat timbunan sampah dan kadar air tanah yang tinggi sehingga tidak cocok digunakan untuk tujuan konstruksi. Di Indonesia, jumlah kubikasi sampah seluruh Indonesia didistribusikan ke 120 TPA besar yang tersebar di seluruh negara. Berdasarakan data Kementrian Lingkungan Hidup dan Kehutananan Indonesia tahun 2020, 65 dari 120 TPA sudah tidak beroperasi dan dibiarkan terbengkalai begitu saja (KemenLHK.go.id, 2020).

Berbeda halnya dengan negara maju seperti Korea Selatan yang berhasil mengubah lahan bekas TPA seluas 272 hektar menjadi Stadiun Piala Dunia 2002 dengan konsep eco park di sekitarnya (Yoo et al, 2014). Hal ini menunjukkan bahwa lahan luas yang terbengkalai di Indonesia juga seharusnya dapat dimanfaatkan dalam peruntukkan konstruksi. 
Dalam menangani kualitas tanah yang rendah pada tanah landfill maka diperlukan pengukuran batas kemampuan tanah landfill dalam menangani beban di atasnya. Untuk mengetahui hal tersebut, pengujian akan menggunakan permodelan beban yang dimulai dengan beban struktur 1 lantai, meningkat secara berurutan hingga beban struktur 4 lantai. Fondasi yang digunakan untuk struktur bangunan tersebut adalah fondasi dangkal yang cocok pada model struktur dengan jumlah tingkat yang tidak banyak.

Stabilisasi tanah secara kimiawi menjadi salah satu metode perbaikan yang dapat meningkatkan parameter tanah tanpa harus merombak struktur lapisan tanah. Pencampuran senyawa kimia ke dalam tanah menjadi salah satu keuntungan karena tidak memerlukan upaya yang besar terhadap lapisan tanah. Metode pencampuran Sodium Hidroksida dan batu kapur dipilih sebagai metode stabilisasi kimia terhadap tanah landfill. Dalam penelitian, efek penurunan akibat adanya pembusukkan sampah diabaikan karena tidak dapat diperkirakan dengan pasti, dan memerlukan analisis komposisi tanah tersendiri mengenai hal tersebut.

Dengan mempertimbangkan latar belakang di atas, maka dihasilkan rumusan-rumusan masalah sebagai berikut:

1. Menghitung penurunan yang terjadi pada tanah asli dan penurunan yang terjadi setelah stabilisasi dengan Sodium Hidroksida maupun batu kapur

2. Membandingkan hasil penurunan sebelum dan sesudah stabilisasi dan menganalisis kemungkinan konstruksi di atas tanah landfill

Berdasarkan rumusah masalah di atas, maka dapat disimpulkan bahwa tujuan penelitian ini adalah sebagai berikut:

1. Untuk mengetahui besarnya penurunan yang terjadi pada tanah asli dan pada tanah terstabilisasi

2. Untuk mengetahui kemungkinan konstruksi di atas tanah landfill sebelum dan sesudah stabilisasi

\section{Perbaikan Tanah}

Perbaikan adalah stabilisasi tanah yang dilakukan untuk memperbaiki dan mempertahankan kemampuan kinerja tanah sesuai syarat teknis yang dibutuhkan, menggunakan bahan additive (kimiawi), pencampuran tanah (regradation), pengeringan tanah (dewatering) atau melalui penyaluran energi statis maupun dinamis ke tanah (fisik).

Stabilisasi kimia dilakukan dengan menambahkan bahan kimia tertentu dengan material tanah, sehingga terjadi reaksi kimia antara tanah dengan bahan pencampurnya, yang bertujuan menghasilkan material baru yang memiliki sifat teknis lebih baik dari sebelumnya. Metode perbaikan tanah dengan bahan kimia dapat menggunakan larutan kimia atau bubu kimia (powder), yang dicampurkan ke tanah yang akan diperbaiki, dengan beberapa metode pencampuran yang disesuikan kondisi bahan stabilizer maupun kondisi tanahnya (Singh, 2019).

Berdasarkan jurnal penelitian "Stabilization of Soils Using Sodium Hydroxide" tahun 2017, penambahan $\mathrm{NaOH}$ pada tanah signifikan pada range 5-10 \% NaOH. Output yang dihasilkan bervariasi mulai dari 16\% hingga $110 \%$ peningkatan nilai $\mathrm{S}_{\mathrm{u}}$ tanah. Pengurangan kadar air yang dihasilkan maksimum sebesar 13,562\% pada tanah clay lunak (Hussain, 2017). Penelitian lain menunjukkan bahwa penambahan kadar $\mathrm{NaOH}$ di atas kadar $10 \%$ menunjukkan adanya penurunan parameter kekuatan tanah (Gunarso, 2017).

Berdasarkan jurnal penelitian "An Experimental Study of Soil Stablisation Using Sodium Hydroxide Additve” tahun 2012, variasi penambahan $\mathrm{NaOH}$ pada clay sebesar 2, 4, 6, 8, 10\% menunjukkan kadar optimum penambahan pada $\mathrm{NaOH} 6 \%$. Pengurangan maksimum kadar air pada $\mathrm{NaOH} 6 \%$ dicapai sebesar $14 \%$. Peningkatan $\mathrm{S}_{\mathrm{u}}$ dicapai pada range $20 \%$ - 108\% (Kumar, 2012).

Berdasarkan jurnal "The Effect of Quicklime Stabilization on Soil Properties" menggunakan sampel brownish clay dan yellowish silty clay dengan variasi 2-8 \% batu kapur menunjukkan bahwa variasi campuran batu kapur pada 3$4,5 \%$ optimum mengurangi water content pada tanah. Pengurangan water content bervariasi pada range $10,8 \%$ $18,1 \%$ pada dari kadar air mula - mula. Peningkatan nilai $S_{u}$ tanah bervariasi pada prosentasi $46,98 \%-59,95 \%$ (Tatiana dan Ernst, 2016).

Sementara pada jurnal "Impact of Soil Stabilization with Lime" penambahan batu kapur dilakukan dengan variasi 2 , 4, $6 \%$ pada silt dan clay menunjukkan peningkatan optimum pada $4 \%$ dengan pengurangan kadar air hingga $20 \%$ dan penigkatan $\mathrm{S}_{\mathrm{u}}$ hingga $55 \%$ dari parameter tanah mula - mula.

\section{Fondasi dangkal}

Fondasi dangkal adalah fondasi yang umumnya diletakkan pada kedalaman yang dekat dengan permukaan tanah. Fondasi dangkal cenderung digunakan untuk konstruksi bangunan non-gedung, rumah sederhana atau pada kondisi tanah keras yang berada dekat dengan permukaan tanah (Septiadi, 2020). Pengkategorian yang sering dipakai untuk fondasi dangkal ialah fondasi yang kedalam fondasinya $\left(D_{f}\right)$ berbanding dengan lebar fondasi (B) lebih kecil daripada 4. 
Pada fondasi dangkal berpenampang lingkaran, daya dukung fondasi dapat dihitung dengan pendekatan Terzaghi (1943), yaitu:

$$
q_{u l t}=1,3 c^{\prime} N_{c}+q N_{q}+0,3 \gamma N_{\gamma}
$$

dengan $\mathrm{q}_{\mathrm{ult}}=$ daya dukung fondasi, $\mathrm{c}^{\prime}=$ kohesi, $\mathrm{q}=$ tegangan tanah, $\mathrm{N}_{\mathrm{c}}=$ faktor kohesi, $\mathrm{N}_{\mathrm{q}}=$ faktor beban tambahan, dan $\mathrm{N}_{\gamma}=$ faktor berat jenis tanah.

\section{Penurunan (settlement)}

Pada umumnya, penurunan yang terjadi yang diperhatikan adalah penurunan langsung dan penurunan konsolidasi primer, hal ini diakibatkan konsolidasi sekunder sulit diperkirakan karena membutuhkan jangka waktu yang sangat lama untuk terjadi dan cenderung kecil (Das, 2010). Pada gambar 1, terlihat bawa tahap III merupakan konsolidasi sekunder yang terjadi dalam waktu yang cenderung lebih lama dibanding tahap I dan II, maka dari itu konsolidasi sekunder sering diabaikan. Akan tetapi, pada penelitian ini, seluruh penurunan dihitung dikarenakan penurunan konsolidasi sekunder pada tanah landfill diperkirakan cukup besar akibat kualitas tanah yang buruk.

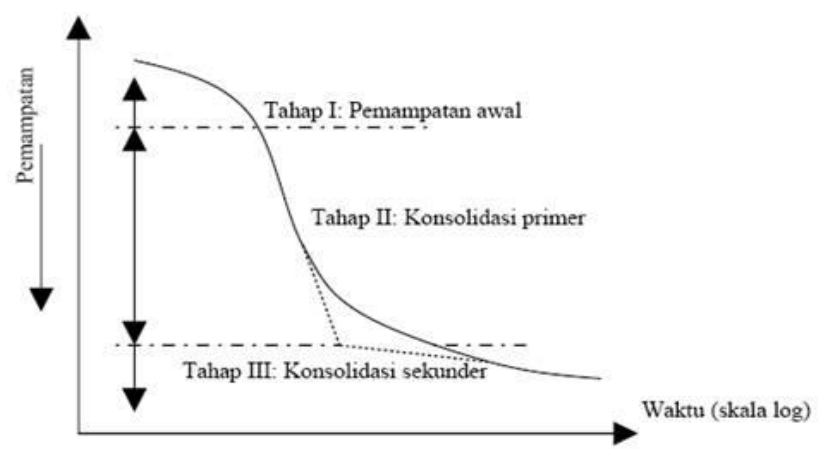

Gambar 1. Grafik perbandingan penurunan tanah terhadap waktu

Penurunan langsung pada tanah landfill dapat dihitung menggunakan pendekatan dari persamaan Janbu, Bjerrum, dan Kjaernsli (1956) dengan persamaan:

$$
\mathrm{S}_{\mathrm{i}}=\mu_{0} \mu_{1} \frac{q_{n} B}{E}
$$

dengan $\mathrm{S}_{\mathrm{i}}=$ penurunan langsung, $\mu_{0}=$ faktor koreksi kedalaman, $\mu_{1}=$ faktor koreksi ketebalan lapisan $(\mathrm{H}), \mathrm{q}_{\mathrm{n}}=$ tekanan fondasi netto, dan $\mathrm{E}=$ modulus elastisitas.

Nilai $\mu_{0}$ didapat dengan korelasi grafik pada gambar 2 , sedangakan nilai $\mu_{1}$ didapat melalui korelasi grafik pada gambar 3 .

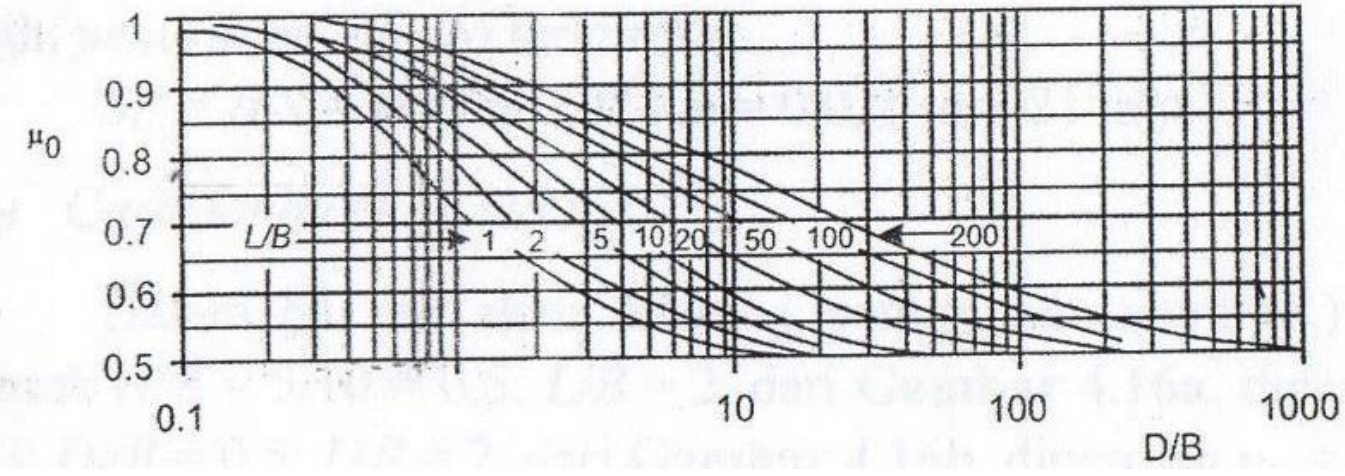

Gambar 2. Grafik hubungan $\mu_{0}$ dengan H/B (Sumber: Janbu,1956 dalam Das, 2014) 


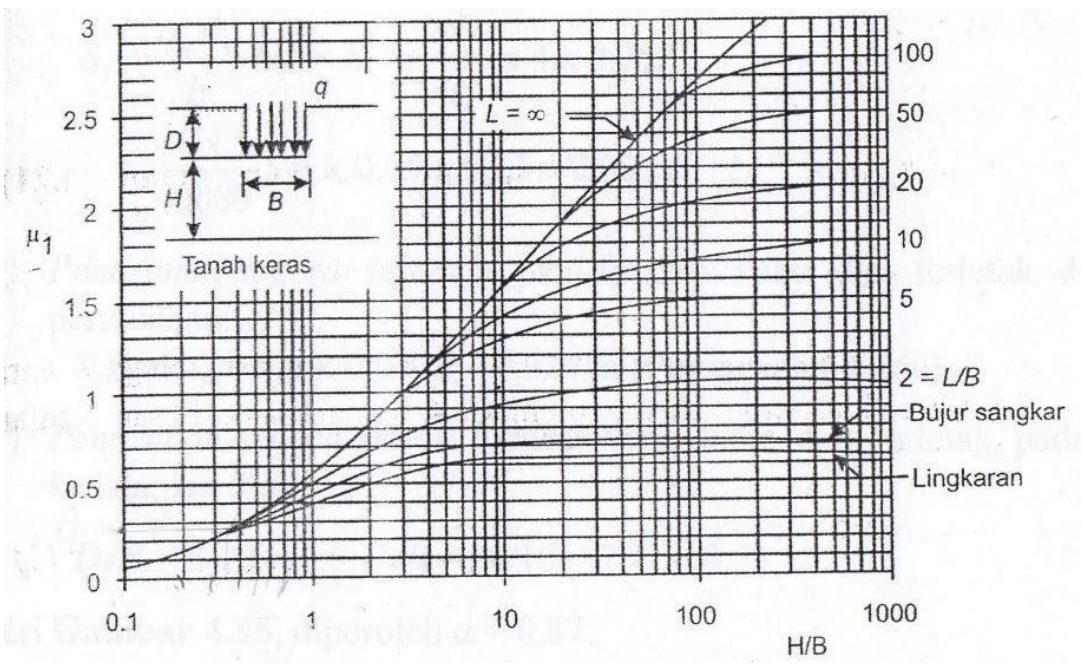

Gambar 3. Grafik hubungan $\mu_{1}$ dengan $\mathrm{D}_{\mathrm{f}} / \mathrm{B}$ (Sumber: Janbu,1956 dalam Das, 2014)

Konsolidasi primer terjadi bergantung pada kondisi tanah, pada keadaan Normal Consolidated di mana $\mathrm{P}_{\mathrm{o}}{ }^{\prime}<\mathrm{P}_{\mathrm{c}}$, besar konsolidasi dapat dihitung dengan persamaan:

$$
\mathrm{S}_{\mathrm{c}}=\frac{C_{c} H_{S}}{1+e_{0}} \log \frac{P_{0}^{\prime}+\sigma_{\max }}{P_{0^{\prime}}}
$$

dengan $\mathrm{S}_{\mathrm{c}}=$ konsolidasi primer, $\mathrm{C}_{\mathrm{c}}=$ indeks pemampatan, $\mathrm{H}=$ tebal lapisan, $\mathrm{P}_{\mathrm{o}}{ }^{\prime}=$ tekanan overburden efektif, $\sigma_{\max }$ = tegangan maksimum beban.

Pada keadaan Overconsolidated, konsolidasi dapat dihitung dengan persamaan:

$$
\begin{gathered}
\mathrm{S}_{\mathrm{c}}=\frac{C_{S} H_{S}}{1+e_{0}} \log \frac{P_{c^{\prime}}}{P_{0^{\prime}}}+\frac{C_{c} H_{C}}{1+e_{0}} \log \frac{P_{0}^{\prime}+\sigma_{\max }}{P_{c^{\prime}}},\left(P_{o}^{\prime}<P_{c}^{\prime}<P_{0}^{\prime}+\sigma_{\max }\right) \\
\mathrm{S}_{\mathrm{c}}=\frac{C_{S} H_{S}}{1+e_{0}} \log \frac{P_{0}^{\prime}+\sigma_{\max }}{P_{c^{\prime}}},\left(P_{o}^{\prime}<P_{c}^{\prime}<P_{0}^{\prime}+\sigma_{\max }\right)
\end{gathered}
$$

dengan $\mathrm{C}_{\mathrm{s}}=$ indeks pengembangan dan $\mathrm{P}_{\mathrm{c}}{ }^{\prime}=$ tekanan pra konsolidasi.

Waktu yang dibutuhkan untuk menyelesaikan konsolidasi primer dapat diperkirakan dengan persamaan:

$$
\mathrm{t}_{\mathrm{p}}=\frac{T_{v} H_{d r^{2}}}{C_{v}}
$$

dengan $\mathrm{t}_{\mathrm{p}}=$ waktu konsolidasi primer untuk mencapai penurunan $\mathrm{p} \%, \mathrm{~T}_{\mathrm{v}}=$ faktor waktu, $\mathrm{H}_{\mathrm{dr}}=$ lapisan terkonsolidasi, $\mathrm{C}_{\mathrm{v}}=$ koefisien konsolidasi

Nilai faktor waktu yang digunakan pada derajat konsolidasi dalam p \% didapat dari korelasi menggunakan tabel 1.

Tabel 1. Korelasi derajat konsolidasi dengan faktor waktu $\left(\mathrm{T}_{\mathrm{v}}\right)$

\begin{tabular}{cc}
\hline $\begin{array}{c}\text { Derajat Konsolidasi } \\
\mathrm{U} \%\end{array}$ & $\begin{array}{c}\text { Faktor Waktu } \\
\left(\mathrm{T}_{\mathrm{v}}\right)\end{array}$ \\
\hline 50 & 0,197 \\
60 & 0,287 \\
70 & 0,403 \\
80 & 0,567 \\
90 & 0,848 \\
100 & - \\
\hline
\end{tabular}


Konsolidasi sekunder adalah penurunan tanah yang terjadi setelah penurunan tanah primer selesai. Konsolidasi sekunder terjadi ketika tekanan air pori hilang seluruhnya dan terjadi pemampatan pada butir-butir tanah yang bersifat plastis. Besarnya konsolidasi primer bergantung pada waktu yang dibutuhkan untuk menyelesaikan konsolidasi primer, umur rencana bangunan, dan koefisien konsolidasi sekunder (Ca). Berdasarkan Mesri (1973), korelasi nilai $\mathrm{C}_{\mathrm{a}}$ ' dapat berkisar pada 0,0005-0,001, di mana $\mathrm{C}_{\mathrm{a}}{ }^{\prime} \approx 0,0001$ water content dalam persen (Das, 2014).

Besarnya konsolidasi sekunder dapat dihitung dengan persamaan:

$$
\mathrm{S}_{\mathrm{s}}=\mathrm{C}_{\mathrm{a}}, \mathrm{H}_{\mathrm{c}} \log \left(\frac{t_{2}}{t_{1}}\right)
$$

Dengan $\mathrm{S}_{\mathrm{s}}=$ konsolidasi sekunder, $\mathrm{C}_{\mathrm{a}}{ }{ }=$ koefisien konsolidiasi sekunder efektif, $\mathrm{t}_{2}=$ waktu rencana konsolidasi sekunder, $\mathrm{t}_{1}=$ waktu konsoldiasi primer.

\section{METODE PENELITIAN}

\section{Pengumpulan data}

Pada kajian ini, data yang digunakan berasala dari hasil pengujian data sebuah penelitian tentang profil tanah landfill di Bandung. Data yang diperoleh berupa data uji N-SPT tanah, data sondir dan data tes sampel tanah di laboratorium. Data yang digunakan adalah profil tanah yang berkedalaman hingga 20 meter di bawah permukaan tanah.

\section{Pengolahan data}

Pada tahapan pengolahan data, data yang terkumpul dilakukan korelasi untuk membuat summary data tanah untuk mempermudah perhitungan. Data - data yang belum lengkap didapatkan dengan melakukan pendekatan berdasarkan studi literatur yang ada. Perhitungan beban struktur dilakukan dalam software dan dipilih titik fondasi dengan kombinasi beban vertikal, horizontal dan momen terbesar. Pengolahan data selanjutnya menghitung besar penurunan langsung, konsolidasi primer, dan sekunder yang terjadi pada tanah asli. Perbandingan data dilakukan terhadap penurunan yang terjadi pada tanah asli dan tanah yang telah di stabilisasi menggunakan Sodium Hidroksida dan batu kapur. Efisiensi pengurangan penurunan tanah dihitung dengan membandingkan pengurangan penurunan yang terjadi dengan penurunan tanah asli, dan disajikan dalam persentase.

\section{Diagram alir penelitian}

Diagram alir penelitian ini ditunjukkan pada gambar 4.

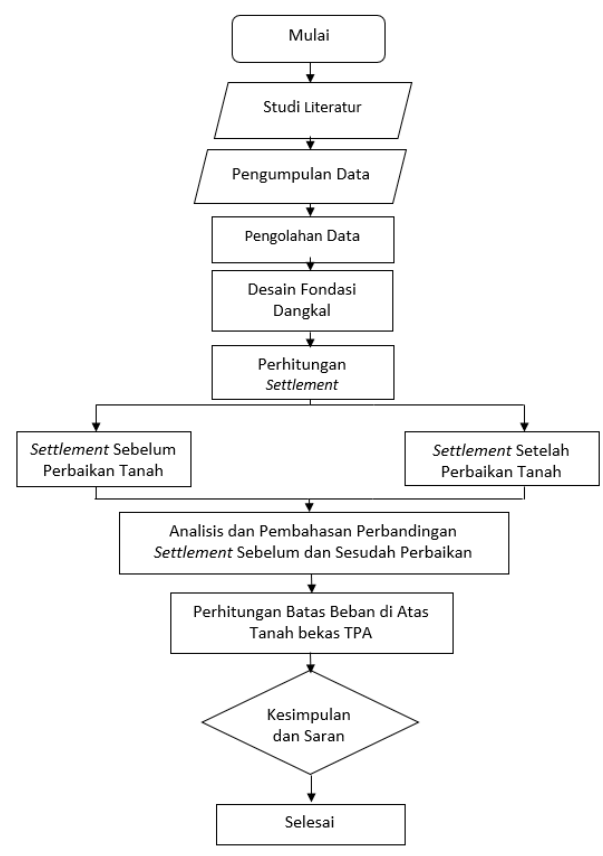

Gambar 4. Diagram alir penelitian 


\section{HASIL DAN PEMBAHASAN}

Berdasarkan hasil perhitungan dan korelasi yang dilakukan, summary data tanah yang digunakan pada penelitian ini sesuai dengan tabel 2 dan 3.

Tabel 2. Summary data tanah (1)

\begin{tabular}{cccccccc}
\hline \multicolumn{2}{c}{ Elevasi } & Tipe & $\mathrm{G}_{\mathrm{s}}$ & $\gamma\left(\mathrm{kN} / \mathrm{m}^{3}\right)$ & $\gamma_{\mathrm{dry}}\left(\mathrm{kN} / \mathrm{m}^{3}\right)$ & $\gamma_{\mathrm{sat}}\left(\mathrm{kN} / \mathrm{m}^{3}\right)$ & $w(\%)$ \\
\hline 0 & 2 & Clay & 2,65 & 19 & 16 & 18,5 & 24 \\
2 & 4 & Sandy silt & 2,65 & 19 & 16 & 18,5 & 24 \\
4 & 5 & Sandy clay & 2,65 & 19 & 16 & 18,5 & 24 \\
5 & 6 & Sandy clay & 2,65 & 19 & 16 & 18,5 & 24 \\
6 & 8 & Sandy silt & 2,65 & 19 & 16 & 18,5 & 24 \\
8 & 10 & Clay & 2,65 & 19 & 16 & 18,5 & 24 \\
10 & 12 & Clay & 2,67 & 19 & 17 & 20 & 20 \\
12 & 15 & Clay & 2,67 & 19 & 17 & 20 & 20 \\
15 & 18 & Clay & 2,67 & 20 & 17 & 20 & 20 \\
18 & 20 & Clay & 2,67 & 20 & 17 & 20 & 20
\end{tabular}

Tabel 3. Summary data tanah (2)

\begin{tabular}{ccccccccccccc}
\hline $\begin{array}{c}\text { Elevasi } \\
(\mathrm{m})\end{array}$ & $\mathrm{e}$ & $\begin{array}{c}\mathrm{C} \\
\left(\mathrm{kg} / \mathrm{m}^{2}\right)\end{array}$ & $\mathrm{C}_{\mathrm{c}}$ & $\mathrm{C}_{\mathrm{s}}$ & $\Phi^{\prime}$ & $\begin{array}{c}\mathrm{S}_{\mathrm{u}} \\
(\mathrm{KPa})\end{array}$ & OCR & $\mathrm{Pc}^{\prime}$ & $\begin{array}{c}\mathrm{E} \\
(\mathrm{MPa})\end{array}$ & $\begin{array}{c}\mathrm{c}^{\prime} \\
(\mathrm{KPa})\end{array}$ & $\begin{array}{c}\mathrm{C}_{\mathrm{v}} \\
\left(\mathrm{m}^{2} / \mathrm{thn}\right)\end{array}$ \\
\hline 0 & 2 & 0,7 & 0,6 & 0,3 & 0,095 & 32 & 25 & 8 & 160 & 8 & 2,5 & 6 \\
2 & 4 & 0,7 & 0,6 & 0,3 & 0,095 & 32 & 25 & 3,6 & 160 & 8 & 2,5 & 6 \\
4 & 5 & 0,7 & 0,6 & 0,3 & 0,095 & 32 & 25 & 2,4 & 160 & 8 & 2,5 & 6 \\
5 & 6 & 0,65 & 0,6 & 0,4 & 0,095 & 27 & 25 & 2,4 & 160 & 8 & 5,5 & 3 \\
6 & 8 & 0,65 & 0,6 & 0,4 & 0,095 & 27 & 25 & 2,4 & 160 & 8 & 5,5 & 3 \\
8 & 10 & 0,65 & 0,6 & 0,4 & 0,095 & 27 & 40 & 2,4 & 240 & 12 & 5,5 & 3 \\
10 & 12 & 0,6 & 1,35 & 0,2 & 0,095 & 30 & 40 & 2,4 & 240 & 12 & 8 & 6 \\
12 & 15 & 0,6 & 1,35 & 0,2 & 0,095 & 30 & 55 & 2 & 280 & 24 & 8 & 6 \\
15 & 18 & 0,6 & 1,35 & 0,15 & 0,095 & 30 & 55 & 2 & 280 & 24 & 13,5 & 6 \\
18 & 20 & 0,6 & 1,35 & 0,15 & 0,095 & 30 & 100 & 3 & 560 & 24 & 20 & 6 \\
\hline
\end{tabular}

Data beban rencana dengan draft struktur seperti pada gambar 5. Beban rencana menggunakan beban tipikal pada tiap lantai, mulai dari lantai 1 hingga lantai 4 beserta dengan atap. Beban atap menggunakan atap yang terbuat dari baja ringan. Pada permodelan beban dilakukan secara berurutan mulai dari beban 1 lantai, 2 lantai, 3 lantai, hingga 4 lantai yang diaplikasikan di software. 

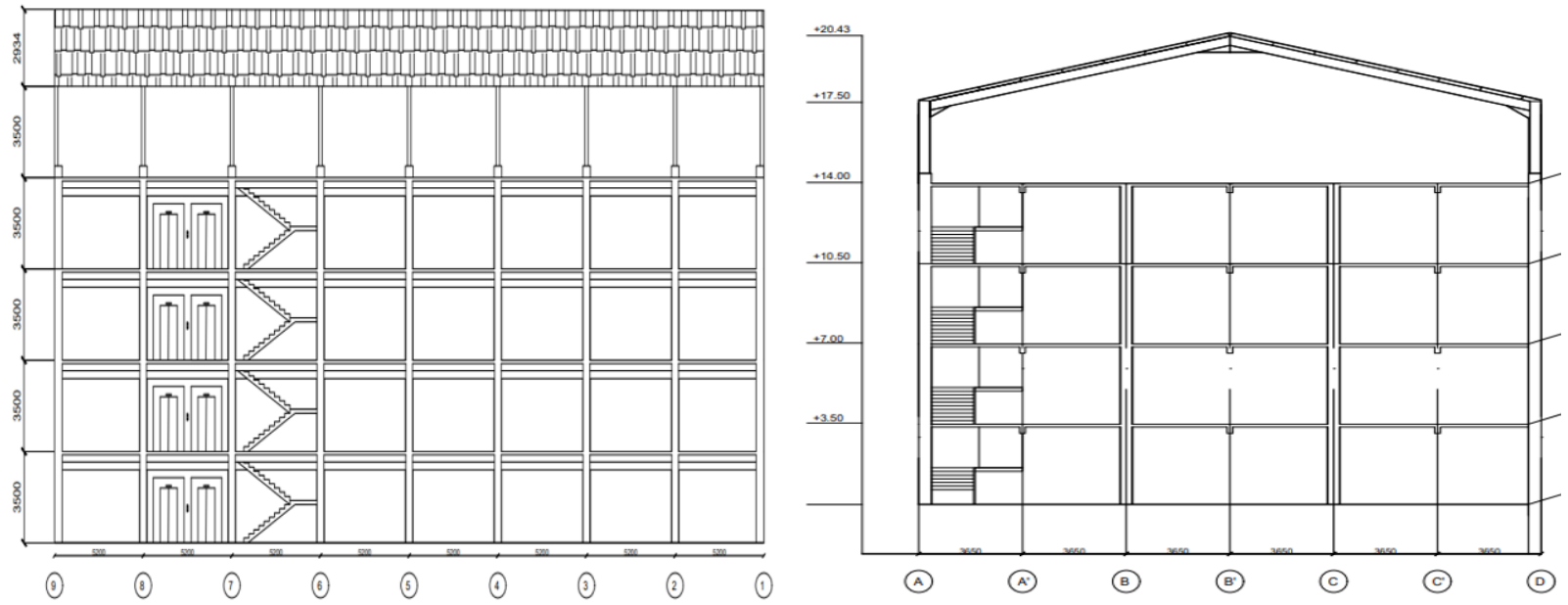

Gambar 5. Tampak samping (kiri) dan tampak depan (kanan) dari struktur bangunan

Dari hasil input pada software, didapati beban maksimum fondasi pada tiap tipe beban, lalu diperhitungkan daya dukung fondasi untuk menahan beban serta desain fondasi sesuai dengan tabel 4.

Tabel 4. Beban maksimum pada berdasarkan tipe beban dan dimensi fondasi

\begin{tabular}{cccccc}
\hline Beban & $\mathrm{V}(\mathrm{kN})$ & $\mathrm{H}(\mathrm{kN})$ & $\mathrm{M}(\mathrm{kNm})$ & $\mathrm{D}_{\mathrm{f}}(\mathrm{m})$ & $\mathrm{B}(\mathrm{m})$ \\
\hline 1 lantai + atap & 423,383 & 87,987 & 92,1393 & 1 & 2 \\
2 lantai + atap & 755,828 & 69,2584 & 72,907 & 1 & 2 \\
3 lantai + atap & 1086,77 & 72,8874 & 76,8613 & 1 & 2,5 \\
4 lantai + atap & 1417,46 & 71,7236 & 75,6818 & 2 & 2.5 \\
\hline
\end{tabular}

Perhitungan settlement dilakukan berdasarakan studi literatur yang ada, didapati penurunan total yang terjadi pada tanah asli terdapat pada tabel 5.

Tabel 5. Penurunan pada tanah asli

\begin{tabular}{ccccccc}
\hline Beban & $\mathrm{D}(\mathrm{m})$ & $\mathrm{B}(\mathrm{m})$ & $\mathrm{Si}(\mathrm{cm})$ & $\mathrm{Sc}(\mathrm{cm})$ & $\mathrm{Ss}(\mathrm{cm})$ & Stotal $(\mathrm{cm})$ \\
\hline 1 lantai + atap & 1 & 2 & 7,3314 & 18,6944 & 3,4899 & 29,5157 \\
2 lantai + atap & 1 & 2 & 8,5001 & 20,7824 & 3,4899 & 32,7724 \\
3 lantai + atap & 1 & 2,5 & 9,1310 & 19,6324 & 3,4899 & 32,2533 \\
4 lantai + atap & 2 & 2,5 & 13,0788 & 22,7989 & 3,5608 & 39,4386 \\
\hline
\end{tabular}

Dari tabel 5, didapati bahwa semua penurunan dengan variasi tipe beban lebih besar dari $15 \mathrm{~cm}$, maka dilakukan stabilisasi menggunakan metode pencampuran Sodium Hidroksida maupun batu kapur. Pencampuran Sodium Hidroksida digunakan kadar 6\% diambil variasi pengurangan kadar air sebesar $14 \%$ dengan range peningkatan $S_{\mathrm{u}}$ sebesar 20\%, 60\%, dan 110\%. Sedangkan, stabilisasi dengan batu kapur 3-4,5\% diambil variasi peningkatan $\mathrm{S}_{\mathrm{u}}$ sebesar 55\% dengan range pengurangan kadar air sebesar $11 \%$ dan $18 \%$. 
Penurunan total pada tanah stabilisai Sodium Hidroksida 6\% ditunjukkan pada tabel 6.

Tabel 6. Penurunan total pada tanah terstabilisasi sodium hidroksida $6 \%$

\begin{tabular}{cccccc}
\hline Beban & Peningkatan Su & $\mathrm{Si}(\mathrm{cm})$ & $\mathrm{Sc}(\mathrm{cm})$ & $\mathrm{Ss}(\mathrm{cm})$ & Stotal $(\mathrm{cm})$ \\
\hline \multirow{3}{*}{ 1 lantai + atap } & $20 \%$ & 6,1095 & 16,3028 & 3,4899 & 24,7895 \\
& $60 \%$ & 4,5821 & 15,1901 & 3,4899 & 23,2621 \\
& $110 \%$ & 3,4911 & 15,1901 & 3,4899 & 22,1711 \\
\hline \multirow{3}{*}{ lantai + atap } & $20 \%$ & 7,0834 & 18,1053 & 3,4899 & 28,6786 \\
& $60 \%$ & 5,3125 & 16,6331 & 3,4899 & 25,4356 \\
3 lantai + atap & $110 \%$ & 4,0477 & 16,4793 & 3,4899 & 24,0168 \\
& $20 \%$ & 7,6092 & 17,2157 & 3,4899 & 28,3148 \\
& $60 \%$ & 5,7069 & 16,2298 & 3,4899 & 25,4265 \\
& $110 \%$ & 4,3481 & 16,2298 & 3,4899 & 24,0678 \\
\hline \multirow{3}{*}{ lantai + atap } & $20 \%$ & 10,899 & 19,0003 & 3,5608 & 33,4602 \\
& $60 \%$ & 8,1743 & 16,8616 & 3,5608 & 28,5967 \\
& $110 \%$ & 6,228 & 16,8616 & 3,5608 & 26,6504
\end{tabular}

Penurunan total pada tanah stabilisasi batu kapur 3-4,5\% ditunjukkan pada tabel 7.

Tabel 7. Penurunan total pada tanah stabilisasi batu kapur 3-4,5\%

\begin{tabular}{cccccc}
\hline Perbaikan & Beban & Si $(\mathrm{cm})$ & $\mathrm{Sc}(\mathrm{cm})$ & $\mathrm{Ss}(\mathrm{cm})$ & Stotal $(\mathrm{cm})$ \\
\hline & 1 lantai + atap & 4,73 & 15,72 & 3,49 & 23,94 \\
$-11 \% w$ & 2 lantai + atap & 5,484 & 17,505 & 3,49 & 26,478 \\
& 3 lantai + atap & 5,891 & 16,796 & 3,49 & 26,177 \\
& 4 lantai + atap & 8,4348 & 17,45 & 3,561 & 29,449 \\
\hline \multirow{3}{*}{$-18 \% w$} & 1 lantai + atap & 4,73 & 14,484 & 3,49 & 22,703 \\
& 2 lantai + atap & 5,484 & 16,128 & 3,49 & 25,102 \\
& 3 lantai + atap & 5,891 & 15,475 & 3,49 & 24,856 \\
& 4 lantai + atap & 8,438 & 16,077 & 3,561 & 28,076 \\
\hline
\end{tabular}

Berdasarkan data yang diperoleh, dapat dihitung besarnya pengurangan settlement yang terjadi setelah stabilisasi dilakukan seperti pada tabel 8 dan 9.

Tabel 8. Perbandingan penurunan tanah stabilisasi sodium hidroksida $6 \%(\mathrm{NaOH})$

\begin{tabular}{|c|c|c|c|c|c|c|c|}
\hline \multirow[b]{3}{*}{ Beban } & \multicolumn{6}{|c|}{ Stotal $(\mathrm{cm})$} & \\
\hline & \multirow[b]{2}{*}{$\begin{array}{c}\text { Tanah } \\
\text { asli }\end{array}$} & \multicolumn{6}{|c|}{ Perbaikan $\mathrm{NaOH} 6 \%$} \\
\hline & & $\begin{array}{c}20 \% \\
\mathrm{Su}\end{array}$ & $\begin{array}{c}\% \\
\text { pengurangan } \\
\text { settlement }\end{array}$ & $\begin{array}{c}60 \% \\
\mathrm{Su}\end{array}$ & $\begin{array}{c}\% \\
\text { pengurangan } \\
\text { settlement }\end{array}$ & $\begin{array}{c}110 \% \\
\mathrm{Su}\end{array}$ & $\begin{array}{c}\% \\
\text { pengurangan } \\
\text { settlement }\end{array}$ \\
\hline 1 lantai + atap & 29,5157 & 24,7895 & 16,0126 & 23,2621 & 21,1873 & 22,1711 & 24,8836 \\
\hline 2 lantai + atap & 30,0953 & 28,6786 & 4,7073 & 25,4356 & 15,4831 & 24,0168 & 20,1974 \\
\hline 3 lantai + atap & 32,2533 & 28,3148 & 12,2112 & 25,4265 & 21,1660 & 24,0678 & 25,3789 \\
\hline 4 lantai + atap & 39,4386 & 33,4602 & 15,1588 & 28,5967 & 27,4905 & 26,6504 & 32,4255 \\
\hline
\end{tabular}


Tabel 9. Perbandingan penuruan tanah stabilisasi batu kapur 3-4,5\%

\begin{tabular}{cccccc}
\hline & \multicolumn{5}{c}{ Stotal $(\mathrm{cm})$} \\
\cline { 2 - 6 } Beban & Tanah & \multicolumn{4}{c}{ Batu Kapur 3-4,5\% } \\
\cline { 2 - 6 } & asli & $-11 \%$ & $\%$ & $-18 \%$ & $\%$ \\
& & w & $\begin{array}{c}\text { pengurangan } \\
\text { settlement }\end{array}$ & w & $\begin{array}{c}\text { pengurangan } \\
\text { settlement }\end{array}$ \\
\hline 1 lantai + atap & 29,5157 & 23,9398 & 18,8913 & 22,7034 & 23,0802 \\
2 lantai + atap & 30,0953 & 26,4784 & 12,0182 & 25,1016 & 16,5929 \\
3 lantai + atap & 32,2533 & 26,1768 & 18,8399 & 24,8558 & 22,9357 \\
4 lantai + atap & 39,4386 & 29,4486 & 25,3305 & 28,0761 & 28,8105 \\
\hline
\end{tabular}

\section{Hasil perbandingan}

Pada stabilisasi menggunakan Sodium Hidroksida, penurunan total terkecil pada tiap jenis beban sebesar 22,1711 cm untuk beban 1 lantai, 24,0168 cm untuk beban 2 lantai, 24,0678 cm untuk beban 3 lantai, dan 26,6504 cm untuk beban 4 lantai. Persen pengurangan penurunan terkecil sebesar 4,7073\% dan terbesar sebesar 32,4255\%.

Pada stabilisasi meggunakan batu kapur 3-4,5\%, penurunan total terkecil pada tiap jenis beban sebesar $22,7034 \mathrm{~cm}$ untuk beban 1 lantai, 25,1016 cm untuk beban 2 lantai, 24,8558 cm untuk beban 3 lantai, dan $28,0761 \mathrm{~cm}$ untuk beban 4 lantai. Persen pengungan penurunan terkecil sebesar 12,0182\% dan terbesar sebesar 28,8105\%.

\section{KESIMPULAN DAN SARAN}

\section{Kesimpulan}

Berdasarkan hasil penelitian dan analisis penurunan tanah yang terjadi pada fondasi dangkal dapat disimpulkan bahwa:

1. Persen pengurangan penurunan tanah dengan stabilisasi kimiawi metode $\mathrm{NaOH}$ maupun batu kapur meningkat seiring dengan bertambahnya beban yang diterapkan pada fondasi. Hal ini dapat dilihat pada hasil perbandingan di mana pengurangan maksimum sebesar $24,8836 \%$ pada beban 1 lantai, $20,19 \%$ pada beban 2 lantai, 25,3780 \% pada beban 3 lantai, dan 32,4255\% pada beban 4 lantai. Hal ini menunjukkan perbaikan tanah semakin efektif digunakan seiring dengan bertambahnya beban.

2. Perbaikan tanah menggunakan $\mathrm{NaOH} 6 \%$ dapat mencapai persen pengurangan penurunan tanah lebih besar dibandingan perbaikan menggunakan batu kapur 3-4,5\%. Hal ini terlihat dengan \% pengurangan maskimum beban 1 lantai sebesar 24,8836\% pada $\mathrm{NaOH}$ dan 23,0802 \% pada batu kapur. Pada beban 2 lantai sebesar 20,1974\% pada $\mathrm{NaOH}$ dan 16,5929\% pada batu kapur. Pada beban 3 lantai sebesar 25,378 \% pada $\mathrm{NaOH}$ dan 22,9357\% pada batu kapur. Pada beban 4 lantai sebesar $32,4255 \%$ pada $\mathrm{NaOH}$ dan $28,8105 \%$ pada batu kapur. Dapat disimpulkan bahwa perbaikan tanah secara kimiawi menggunakan $\mathrm{NaOH} 6 \%$ lebih baik dari batu kapur 3-4,5\% dalam meningkatkan kemampuan tanah menahan beban dan peningkatan karakteristik tanah.

3. Pada tanah landfill dengan kondisi asli memiliki kepadatan tanah yang sangat buruk, hal ini terlihat dengan penurunan tanah yang terjadi pada beban bangunan 1 lantai sebesar $29,5157 \mathrm{~cm}, 30,0953 \mathrm{~cm}$ pada beban 2 lantai, 32,2533 cm pada beban 3 lantai, dan 39,4386 cm pada beban 4 lantai. Hal ini menunjukkan bahwa tanah landfill tidak dapat digunakan untuk peruntukkan konstruksi tanpa dilakukannya perbaikan tanah terlebih dahulu. Pengujian dengan beban 1 lantai terkecil sekali pun tidak memenuhi persyaratan batas penurunan sebesar $15 \mathrm{~cm}$ pada fondasi.

4. Peningkatan kualitas tanah untuk memperkecil penurunan yang terjadi dengan stabilisasi tanah secara kimiawi menggunakan $\mathrm{NaOH}$ dan batu kapur belum dapat memenuhi persyaratan penurunan maksimum tanah standar yang ditetapkan sebesar $15 \mathrm{~cm}$. Hal ini terlihat pada tabel 8 dan 9 di mana semua penurunan yang terjadi baik sebelum maupun sesudah perbaikan masih melampaui batas penurunan $15 \mathrm{~cm}$. Hal ini disebabkan penurunan total pada tanah asli sangat jauh dari batas penurunan $15 \mathrm{~cm}$, yaitu sebesar 29,5157 $\mathrm{cm}$ untuk penurunan yang paling mendekati batas persyaratan. Maka, diperlukan alternatif perbaikan yang lebih signifikan dalam memperbaiki kemampuan tanah menahan beban.

5. Pemilihan dimensi fondasi berperan penting dalam rangka mengurangi settlement yang terjadi pada tanah landfill. Pada penelitian digunakan digunakan diameter penampang terbesar adalah 2,5 m, apabila penampang diperbesar dapat mengecilkan penurunan tanah yang terjadi hingga memenuhi persyaratan 
penurunan, akan tetapi hal ini menyebabkan overstrength pada desain fondasi di mana daya dukung fondasi jauh melampaui beban sehingga desain tidak efektif atau boros.

6. Stabilisasi kimiawi dengan $\mathrm{NaOH} 6 \%$ mengurangi penurunan total yang terjadi pada tanah landfill. Pada pengujian beban 1 lantai, pengurangan penurunan tanah didapati sebesar 16,0126 \% - 24,8836\% dari penurunan tanah asli, 4,7073 \% - 20,1974 \% pada beban 2 lantai, 12,2112 \% - 25,3789 \% pada beban 3 lantai, dan $12,2112 \%-25,3789 \%$ pada beban 4 lantai.

7. Stabilisasi kimiawi dengan batu kapur 3-4,5\% mengurangi penurunan total yang terjadi pada tanah landfill. Pada pengujian beban 1 lantai, pengurangan penurunan tanah didapati sebesar 18,8913\% - 23,0802\% dari penurunan tanah asli, 12,0812 \% - 16,5929 \% pada beban 2 lantai, 18,8399 \% - 22,9357 \% pada beban 3 lantai, dan 25,3305\% - 28,8105\% pada beban 4 lantai.

8. Perbaikan menggunakan $\mathrm{NaOH} 6 \%$ memiliki rentang variasi pengurangan settlement yang lebih lebar dibandingkan perbaikan menggunakan batu kapur 3-4,5\%. Hal ini dapat dilihat dari tabel 8 dan 9 di mana perbaikan $\mathrm{NaOH} 6 \%$ menghasilkan pengurangan sebesar 16,0126-24,8836\% pada uji beban lantai 1 yang memiliki range sebesar $8 \%$ pada variasi perbaikan, sedangkan batu kapur 3-4,5\% menghasilkan pengurangan sebesar 18,8913 - 23,0802\% yang memili range sebesar 4,2 \% pada variasi perbaikannya. Hal ini juga berlaku pada pengujian dengan beban lantai lebih besar.

\section{Saran}

Dari hasil penelitian yang dilakukan, penulis memberikan beberapa saran untuk melengkapi kekurangan kekurangan yang ada untuk penelitian ke depannya, yaitu:

1. Diperlukannya analisis penurunan menggunakan software sebagai pembanding analisis, dikarenakan banyaknya parameter yang dapat terpengaruh akibat adanya perubahan suatu parameter tertentu yang dapat dilakukan lebih teliti dengan software.

2. Agar mendekati kondisi nyata mengenai tanah landfill diperlukannya pencocokan analisis material material yang terkandung di dalam tanah landfill yang diuji dengan laju dekomposisi material serta ketebalan lapisan material yang ada di lapisan tanah landfill. Hal ini dikarenakan lapisan material yang terdekomposisi dapat menambah besarnya penurunan fondasi yang terjadi.

3. Diperlukannya alternatif perbaikan tanah yang lebih siginifikan dalam meningkatkan parameter kemampuan tanah menahan beban.

4. Diperlukannya penelitian mengenai pengaruh bentuk penampang fondasi dangkal yang lebih efisien dalam mengurangi penurunan yang terjadi pada tanah landfill.

\section{DAFTAR PUSTAKA}

Das, Braja M. Principle of Fondation Seventh editon. Canada: Thomson Canada Limited, 2010.

Das, Braja M., Khaled. Principles of Geotechnical Engineering. ( $8^{\text {th }}$ edition). United States of America. Global Engineering, 2014.

Gunarso, Andreas, dan Rizqi Nupriyanto. "Stabilisasi Tanah Lempung Ekspansif Dengan Campuran Larutan $\mathrm{NaOH}$ 7,5\%.” Jurnal Karya Teknik Sipil, vol. 6, no. 2, 2017, pp. 238-45.

Hussain, Saddam. "Stabilization of Expansive Soil Using Sodium Hydroxide.” International Interdisciplinary Coference on Science Technology Engineering Management, 2017, pp. 432-39.

Kementrian Lingkungan Hidup dan Kehutanan. (TPA) Sampah - Data Alam - Kementrian Lingkungan Hidup dan Kehutanan. 2020. 26 November 2020. <dataalam.menlhk.go.id>.

Kumar, Mukesh, Singh, J. P, \& Mishra, M. K. An Experimental Study of Soil Stabilisation Using Sodium Hydroxide Additive. 2012: 1-5.

Septiadi, Kevin dan Aniek Prihatiningsih. "Studi Manfaat Daya Dukung Belled Pile Dan Multi-Belled Pile." JMTS: Jurnal Mitra Teknik Sipil, vol. 3, no. 4, 2020, p. 1113, doi:10.24912/jmts.v3i4.8394.

Singh, Gurbaksh dan Ritu Goyal. "Analysis of Heavy Metals Concentration in Landfill Soil.” International Journal of Engineering Research And, vol. V8, no. 12, 2019, pp. 9-10, doi:10.17577/ijertv8is120019.

Tatiana dan Ernest. "The Effect of Quicklime Stabilization on Soil Properties". Agriculture and Agricultural Science Procedia. 10. 2016, pp. 444-451.

Yoo, Kee-Young, Won-ju K., Kyu-yi K., Nanjido Eco Park Restoration from Waste Dumping site. Seoul. Seoul Metropolitan Government, 2014. 